\title{
EFeito de Formulações na AbsorÇão e TranslocaÇão do Glyphosate EM SoJA Transgênica ${ }^{1}$
}

\author{
Effect of Formulations on the Absorption and Translocation of Glyphosate in Transgenic \\ Soybean
}

\author{
SANTOS, J.B. ${ }^{2}$, FERREIRA, E.A. ${ }^{3}$, OLIVEIRA, J.A. ${ }^{4}$, SILVA, A.A. ${ }^{5}$ e FIALHO, C.M.T. ${ }^{6}$
}

RESUMO - Este trabalho teve como objetivo avaliar a absorção e translocação de glyphosate em diferentes formulações por plantas de soja (variedade CD 219RR). Para isso, aplicou-se o ${ }^{14} \mathrm{C}$-glyphosate misturado à calda em três formulações comerciais (Roundup Ready ${ }^{\circledR} \mathrm{e}$ R. Transorb ${ }^{\circledR}$, ambas contendo o sal de isopropilamina, e Zapp Qi ${ }^{\circledR}$, formulado à base do sal potássico), quando as plantas apresentavam o segundo trifólio completamente expandido. Transcorridas 4, 16, 40 e 64 horas após a aplicação, as plantas foram coletadas e fracionadas, separando-se a folha de aplicação (trifólio), a parte aérea, as raízes e os nódulos radiculares. $\mathrm{O}{ }^{14} \mathrm{C}$-glyphosate não-absorvido foi recuperado e contado por meio da lavagem da folha (metanol 80\%). Entre as formulações foi observada variação na penetração e na translocação do ${ }^{14} \mathrm{C}$-glyphosate para as diferentes partes avaliadas. Todavia, em todas as formulações a maior absorção se deu nos intervalos posteriores a 16 horas da aplicação. Em relação ao total de herbicida encontrado nas plantas de soja, maior percentual na parte aérea foi observado quando se aplicou o Zapp Qi ${ }^{\circledR}$ (sal potássico) e, nas raízes, o R. Transorb ${ }^{\circledR}$ (sal de isopropilamina). Detectou-se a presença de ${ }^{14} \mathrm{C}$ glyphosate nos nódulos radiculares das plantas em todos os tratamentos, sendo o maior percentual observado quando se utilizou R. Transorb ${ }^{\circledR}, 40$ horas após a aplicação $(0,13 \%$ do total medido ou $0,4 \%$ considerando somente o total presente na planta). Os resultados reforçam a hipótese de que o glyphosate pode prejudicar a simbiose entre rizóbio e soja, uma vez que o microssimbionte também apresenta em seu metabolismo a EPSPS, sensivel a esse herbicida.

Palavras-chave: sal de isopropilamina, sal potássico, soja geneticamente modificada, radioquímico, impacto ambiental da aplicação de herbicidas.

\begin{abstract}
This study was carried out to evaluate the absorption and translocation of glyphosate formulations in genetically modified (GM) soybean by applying ${ }^{14} \mathrm{C}$-glyphosate mixed to three glyphosate formulations (Roundup Ready ${ }^{\circledR}$ and $R$. Transorb ${ }^{\circledR}$ - both with isopropylamine salt, and Zapp $Q i^{\circledR}$, formulated from potassic salt ), using a precision micro syringe. Plant samples were collected after herbicide application (4, 16, 40 and 64 hours) and then divided into leaf (trifolium), aerial part, roots and root nodes for radiation reading. ${ }^{14} \mathrm{C}$-glyphosate that was not absorbed was recovered and counted by washing the leaf with methanol. Penetration and translocation of ${ }^{14} \mathrm{C}$ glyphosate to the different parts evaluated was found to vary. However, the highest absorption was verified at intervals after 16 hours of application. The highest herbicide percentage in the aerial part of the soybean plants was found when Zapp (potassic salt) was applied on the aerial part and when isopropylamin salt was applied on the roots; ${ }^{14} \mathrm{C}$-glyphosate was found in the plant root nodules in all treatments, with the highest percentage being observed with $R$. Transorb ${ }^{\circledR}, 40$ hours after application $(0.13 \%$ of the total measured or $0.4 \%$, considering only the plant total). Results highlight the hypothesis that glyphosate could harm symbiosis between rhizobium and soybean, since the former also shows in its metabolism EPSPS, which is susceptible to this herbicide.
\end{abstract}

Keywords: isopropylamine salt, potassic salt, transgenic soybean, radiochemical, herbicide application environmental impact.

\footnotetext{
Recebido para publicação em 4.10.2006 e na forma revisada em 17.4.2007.

Professor de Agronomia da FAAG/Univale. Rua Israel Pinheiro, 2000, Bairro Universitário, 35020-220, Governador ValadaresMG, <jbarbosa@univale.br>; ${ }^{3}$ Estudante de doutorado - DFT/UFV, <evanderalves@yahoo.com.br>; ${ }^{4}$ Professor Dep. Biologia Geral/UFV, <jalves@ufv.br>; ${ }^{4}$ Professor Dep. Fitotecnia/UFV, <aasilva@ufv.br>; ${ }^{5}$ Acadêmica de Agronomia/UFV, $<$ cintiamtfialho@yahoo.com.br>.
} 


\section{INTRODUÇÃO}

O domínio da tecnologia de produção de soja em regiões tropicais foi conquistado essencialmente no Brasil, onde também se encontra o maior potencial mundial para produção dessa oleaginosa, quando se consideram diversos fatores, incluindo condições edafoclimáticas e a disponibilidade de terras para cultivo. Com a introdução de variedades transgênicas, resistentes ao herbicida glyphosate, houve ampliação da área plantada e maior facilidade no controle da maioria das espécies infestantes. Estima-se que a soja transgênica ocupará mais de $60 \%$ da área total do Brasil na safra 2006/ 2007 (Almeida, 2006). Nessa modalidade de cultivo, o glyphosate é aplicado em pós-emergência da cultura, absorvido e translocado nas plantas sem afetar seu crescimento, promovendo eficiente controle das plantas daninhas nos estádios em que a competição seria extremamente negativa para a cultura.

O glyphosate pertence ao grupo químico dos inibidores da síntese de aminoácidos e contém o N-(phosphonomethyl) glycina como ingrediente ativo (Bridges, 2003). Após sua absorção pelas plantas, é prontamente translocado, juntamente com fotossintatos, dos pontos de aplicação situados nas folhas até drenos distantes. Em plantas sensiveis, o glyphosate atua inibindo a atividade da enzima plastídica 5-enolpiruvilshiquimato-3-fo sfato sintase (EPSPS), responsável pela reação que condensa shiquimato-3-fosfato e fosfoenolpiruvato em 5enolpiruvilshiquimato-3-fosfato (EPSP) e fosfato inorgânico $(\mathrm{Pi})$, na etapa pré-corismato da rota do shiquimato (Shaner $\&$ Bridges, 2003). A rota do shiquimato é ausente em animais, mas é fundamental no metabolismo de plantas, fungos e bactérias para biossíntese dos aminoácidos aromáticos essenciais fenilalanina, tirosina e triptofano (Hinchee et al., 1993). Estima-se que mais de $20 \%$ de todo o carbono fixado pela fotossintese passe por essa rota, destinando-se à sintese dos aminoácidos aromáticos (Devine et al., 1993).

No caso da soja resistente ao glyphosate, a tolerância ao herbicida foi obtida pela inserção de um gene (AroA) oriundo do genoma de Agrobacterium sp., estirpe CP4, a qual codifica uma variante da EPSPS (CP4 EPSPS), especialmente tolerante à inibição pelo glyphosate
(Padgette et al., 1995). Sob tratamento com esse herbicida, as plantas de soja não são afetadas, devido à ação continuada e sistemática dessa enzima alternativa, insensivel ao produto.

Atualmente estão disponiveis no mercado diversas formulações de glyphosate, porém todas apresentam o mesmo mecanismo de ação, independentemente dos sais utilizados (destacando-se sal de isopropilamina, sal de amônio e sal potássico - este presente exclusivamente na formulação Zapp Qi ${ }^{\circledR}$ ) (Rodrigues \& Almeida, 2005). Para a soja transgênica, está registrada a formulação Roundup Ready ${ }^{\circledR}$, a qual contém o sal de isopropilamina, também presente na formulação Roundup Transorb ${ }^{\circledR}$ (Rodrigues \& Almeida, 2005). Diferentes formulações podem alterar a absorçãoe a translocação do herbicida, influenciando a eficiência de controle (Silva et al., 2006) e seu compor tamento no ambiente (Malkones, 2000; Santos et al., 2005b, 2006).

No Brasil, a simbiose entre plantas de soja e as bactérias do gênero Bradyrhizobium é extremamente importante do ponto de vista econômico, pois permite o cultivo de milhões de hectares dessa cultura sem a adição de adubos nitrogenados. Essa eficiência é o resultado de programas de melhoramento vegetal que priorizaram o desenvolvimento de cultivares com alta especificidade com as estirpes de rizóbio que apresentam alta eficiência na fixação biológica de nitrogênio. Dessa forma, todas as práticas agrícolas nessa cultura deverão considerar os impactos sobre o rizóbio, a fim de possibilitarem a perpetuação dos simbiontes, sem prejuízos para a associação.

No caso particular da soja transgênica, o glyphosate pode ser metabolizado, tendo como produtos primários a sarcosina e o fosfato inorgânico (Barry et al., 1992) ou formando aminometil ácido fosfônico e glioxilato (Hoagland, 1980), todos compostos não-tóxicos. Todavia, considerando a presença dos bacteróides, associados às raízes da soja, no momento da aplicação desse produto e a sensibilidade das estirpes comercialmente recomendadas para inoculação em sementes no Brasil (Santos et al., 2004, 2005b), estudos da translocação do glyphosate para as raízes, inclusive nos nódulos radiculares, se fazem necessários. 
Diante do exposto, este trabalho teve como objetivo avaliar a absorção e a translocação do glyphosate em plantas de soja resistentes a esse herbicida, considerando formulações à base de sal de isopropilamina e potássico.

\section{MATERIAL E MÉTODOS}

O experimento foi realizado em casa de vegetação e avaliado em laboratório entre janeiro e agosto de 2006. Plantas de soja da variedade CD 219RR, contendo o gene CP4EPSPS, tolerante ao glyphosate, foram cultivadas em vasos com seis litros de substrato previamente preparado (terra) para o adequado crescimento da cultura. Depositaram-se quatro sementes por vaso, sendo posteriormente realizado o desbaste das plântulas, deixando-se duas plantas por vaso.

Aos 25 dias após a emergência (DAE), quando as plantas de soja apresentavam o segundo trifólio completamente expandido (estádios $\mathrm{V}_{2}$ $\mathrm{V}_{3}$ ), aplicou-se o ${ }^{14} \mathrm{C}$-glyphosate em mistura com três formulações de glyphosate (Roundup Ready $^{\circledR}$ e R. Transorb ${ }^{\circledR}$, ambas contendo o sal de isopropilamina, e Zapp $\mathrm{Qi}^{\circledR}$, formulado à base do sal potássico). Para isso, utilizou-se microsseringa de precisão, sendo aplicados $100 \mu \mathrm{L}$ por planta de calda contendo o ${ }^{14} \mathrm{C}$-glyphosate (com radioatividade em torno de 50.000 contagens por minuto-cpm) e 7,1 mg do glyphosate (equivalente ácido - e.a.) para cada formulação comercial. Essa concentração equivale a 1.000 g e.a. ha-1, sendo aplicada sobre o segundo trifólio de cada planta.

A avaliação da absorção e translocação do ${ }^{14} \mathrm{C}$ glyphosate na soja foi realizada em diferentes intervalos de tempo $(4,16,40$ e 64 horas após a aplicação). A cada intervalo as plantas foram coletadas e fracionadas em folha de aplicação (trifólio), parte aérea, raízes e nódulos radiculares. A folha de aplicação (trifólio) foi lavada com 10,0 mL de solução 8:2 metanol: água, para recuperação do produto não-absorvido. Após separadas e identificadas, todas as partes da planta foram secas em estufa a $50{ }^{\circ} \mathrm{C}$, por 48 horas, para obtenção da massa seca. Em seguida, procedeu-se à moagem das amostras em moinho de bola, até apresentarem textura equivalente a 200 mesh. Depois disso, subamostras de aproximadamente $100 \mathrm{mg}$ de massa seca de cada componente foram colocadas em frascos de $20 \mathrm{~mL}$, para contagem da cintilação líquida. Para isso, as amostras foram homogeneizadas com $1 \mathrm{~mL}$ de Triton-X-100 ${ }^{\circledR}$ por 14 segundos em vortex, adicionando, em seguida, $5 \mathrm{~mL}$ de coquetel de cintilação (Sigma Fluor $\left.{ }^{\circledR}\right)$, sendo novamente submetido a homogeneização. Após essa etapa, as amostras foram colocadas em espectrômetro de cintilação líquida, modelo Beckman 6500.

Os valores da radioatividade expressos em cpm, encontrados na solução de lavagem e em cada parte da planta, foram convertidos em porcentagem em relação à radioatividade total medida. Em seguida, considerando o total de glyphosate efetivamente absorvido pelas plantas, os valores de ${ }^{14} \mathrm{C}$-glyphosate foram convertidos em porcentagem em relação ao total presente na planta. Relacionou-se então com as quantidades medidas na folha tratada, parte aérea, raízes e nódulos. Foi realizada análise de variância, sendo as médias, quando significativas, comparadas pelo teste de Tukey a 5\% de probabilidade.

\section{RESULTADOS E DISCUSSÃO}

Avaliando a velocidade de absorção do ${ }^{14} \mathrm{C}$ glyphosate em função das formulações, constataram-se diferenças no percentual do herbicida no interior das plantas em função do sal (Figura 1). A maior diferença foi observada a 16 horas da aplicação, quando o sal potássico passou a representar maior quantidade relativa na massa seca total das plantas. Formulações de herbicidas à base de sais amínicos são relatadas como mais livremente difundidas pela cutícula, quando comparadas aos correspondentes sais potássicos ou sódicos (Wanamarta et al., 1993). No entanto, em torno de 40 horas após a aplicação, verificou-se tendência de estabilização das quantidades de produto radiomarcado nas plantas, sendo o maior valor observado nas formulações R. Transorb ${ }^{\circledR}$ (sal de isopropilamina) e Zapp Qi ${ }^{\circledR}$ (sal potássico).

Dentre os produtos no mercado brasileiro, formulados à base de glyphosate, R. Transorb ${ }^{\circledR}$ e Zapp Qi ${ }^{\circledR}$ são relatados como mais eficientes no controle de plantas daninhas quando o intervalo entre a aplicação e a ocorrência de chuvas é pequeno, dada a maior velocidade de 


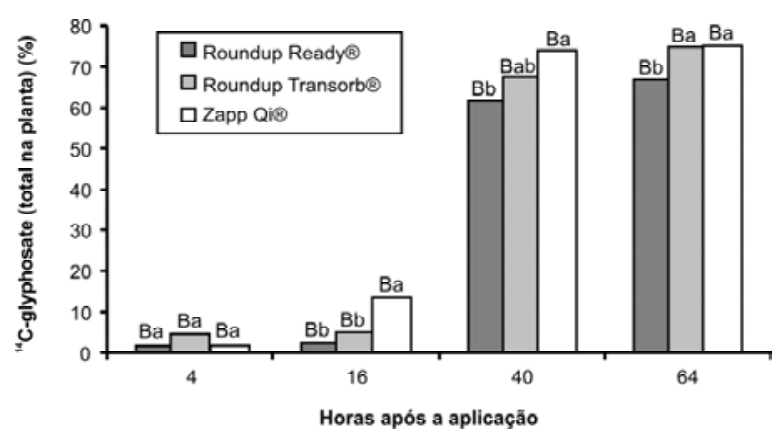

Figura $1-{ }^{14} \mathrm{C}$-glyphosate presente na massa seca total de plantas de soja tratadas com formulações desse herbicida e posterior quantificação em intervalos de tempo (horas após a aplicação). Colunas sob letras maiúsculas e minúsculas representam médias que não diferem entre si pelo teste de Tukey $(\mathrm{p} \leq 0,05)$, respectivamente para cada formulação entre as horas e para as formulações dentro de cada hora de avaliação.

penetração (Jakelaitis et al., 2001; Rodrigues $\&$ Almeida, 2005). Nesta pesquisa, considerando a primeira avaliação realizada quatro horas após a aplicação do glyphosate, nota-se que R. Transorb ${ }^{\circledR}$ apresentou absorção sensivelmente maior do que as demais formulações; entretanto, por volta de 24 horas da aplicação, ${ }^{14} \mathrm{C}$ glyphosate com sal potássico apresentou proporção bem mais elevada na planta, comparado àqueles à base do sal de isopropilamina (Figura 1). A formulação Roundup Ready ${ }^{\circledR}$ se comportou como R. Transorb ${ }^{\circledR}$, provavelmente devido à equivalência de seus sais, porém o primeiro apresentou menor absorção final, comparado ao segundo. Pline \& Hatzios (1999) avaliaram a velocidade de absorção do R. Ready ${ }^{\circledR}$ em plantas de soja com adição de sulfato de amônio ou ácido pelargônico como surfatantes. Em ambos os casos, mais de $40 \%$ do ${ }^{14} \mathrm{C}$ glyphosate havia penetrado após 24 horas da aplicação. Neste trabalho, considerando 24 horas após a aplicação dos herbicidas, à exceção do sal potássico, as demais formulações apresentaram percentual total na planta inferior a $20 \%$. O glyphosate pode sofrer considerada variação na velocidade de absorção e atuação, dependendo dos surfatantes já presentes ou adicionados à calda no momento da aplicação. Em trabalhos realizados por Molin \& Hirase (2005), simulando chuva após a aplicação de glyphosate, os autores observaram que a adição de uma mistura de surfatantes (polioxietileno amino e éter, entre outros) ao glyphosate promoveu o controle eficiente de Sorghum halepense, chegando a $80 \%$, com simulação de chuva 15 minutos após a aplicação.

Grande parte dos herbicidas ficou retida na superficie das folhas tratadas, uma vez que, mesmo 16 horas após a aplicação, mais de $80 \%$ do ${ }^{14} \mathrm{C}$ glyphosate aplicado foi recuperado na solução de lavagem (Figura 2). No entanto, a maior penetração ocorreu entre 16 e 40horas, o que pode ser confirmado pelo decréscimo na quantidade do produto recuperado da folha de aplicação do herbicida (Figura 2). Esse comportamento foi o mesmo para todas as formulações. Considerando a eficácia do glyphosate, não é necessário grande quantidade de produto absorvido para acarretar a morte de plantas sensiveis. Ferreira et al. (2006) verificaram que oito horas após a aplicação de ${ }^{14} \mathrm{C}$-glyphosate em plantas de azevém sensiveis a esse herbicida somente $5 \%$ haviam penetrado; contudo, isso foi suficiente para levar a planta à morte. Esses resultados sugerem que concentrações muito abaixo daquela aplicada em campo são suficientes para promover a morte das espécies sensiveis ao glyphosate, considerando que a ocorrência de chuvas, mesmo quatro horas após a aplicação, não impede a eficiência de controle observada para esse produto (Rodrigues \& Almeida, 2005).

Levando-se em conta a quantidade efetivamente presente no interior das plantas, em relação ao total medido durante os ensaios, pode-se perceber o comportamento semelhante entre as formulações quanto à quantidade presente na folha que recebeu a aplicação (Figura 3). Entretanto, na avaliação da translocação e acúmulo do produto nas diferentes partes da planta, verifica-se considerável variação entre as formulações no decorrer do tempo (Figuras 4 e 5). Considerando somente a folha que recebeu a aplicação do produto, o maior percentual foi observado depois de 16 horas da aplicação. Nas leituras efetuadas 4 e 16 horas após a aplicação, constatou-se baixo percentual nas folhas, independentemente do sal presente na formulação, comprovando os resultados observados na avaliação da solução de lavagem (Figura 3). É provável que, à medida que o produto foi absorvido, foi sendo prontamente translocado 


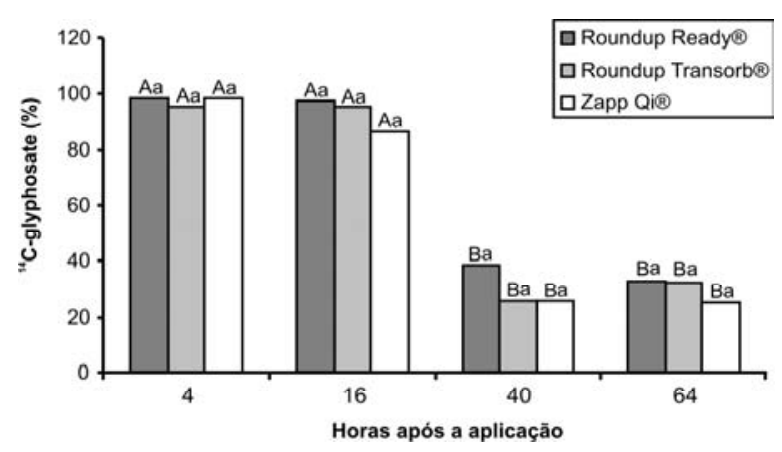

Figura $2-{ }^{14} \mathrm{C}$-glyphosate presente na solução de lavagem das folhas de soja (em relação ao total medido) tratadas com formulações desse herbicida e posterior quantificação em intervalos de tempo. Colunas sob letras maiúsculas e minúsculas representam médias que não diferem entre si pelo teste de Tukey $(p \leq 0,05)$, respectivamente para cada formulação entre as horas e para as formulações dentro de cada hora de avaliação.

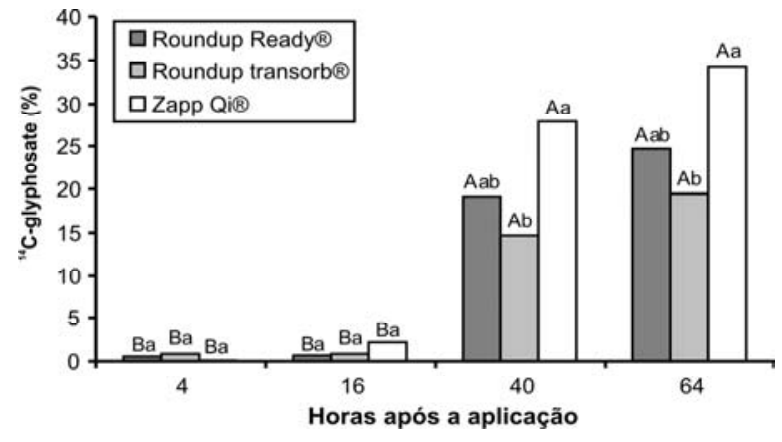

Figura $4-{ }^{14} \mathrm{C}$-glyphosate presente na parte aérea de plantas de soja (em relação ao total medido) que receberam a aplicação de formulações desse herbicida e posterior quantificação em intervalos de tempo. Colunas sob letras maiúsculas e minúsculas representam médias que não diferem entre si pelo teste de Tukey $(\mathrm{p} \leq 0,05)$, respectivamente para cada formulação entre as horas e para as formulações dentro de cada hora de avaliação.

para as raízes, haja vista o acúmulo na parte aérea ter sido mínimo até 16 horas (Figura 4). Nesse mesmo tempo, a quantidade nas raízes foi sensivelmente maior, apresentando diferenças entre as formulações. Após 16 horas da aplicação, o sal potássico se mostrou em maior proporção nas raízes (Figura 5). Em intervalos posteriores, houve variação entre as formulações e entre as horas (40 e 64) na quantidade presente na parte aérea e nas raízes das plantas de soja, considerando o total de ${ }^{14} \mathrm{C}$ glyphosate medido (Figuras 5 e 6). $\mathrm{Na}$

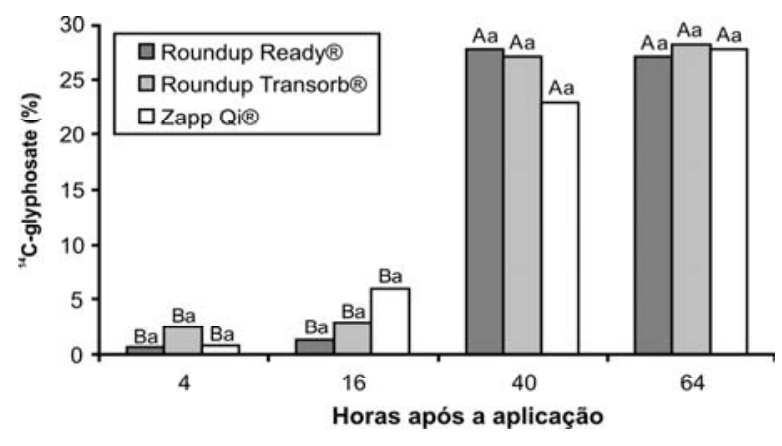

Figura $3-{ }^{14} \mathrm{C}$-glyphosate presente na folha de soja (em relação ao total medido) que recebeu a aplicação de formulações desse herbicida e posterior quantificação em intervalos de tempo. Colunas sob letras maiúsculas e minúsculas representam médias que não diferem entre si pelo teste de Tukey $(p \leq 0,05)$, respectivamente para cada formulação entre as horas e para as formulações dentro de cada hora de avaliação.

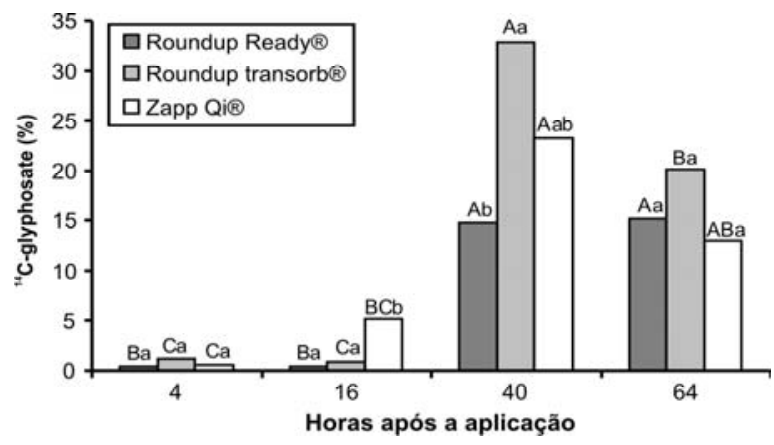

Figura $5-{ }^{14} \mathrm{C}$-glyphosate presente nas raízes de plantas de soja (em relação ao total medido) que receberam aplicação de formulações desse herbicida e posterior quantificação em intervalos de tempo. Colunas sob letras maiúsculas e minúsculas representam médias que não diferem entre si pelo teste de Tukey $(p \leq 0,05)$, respectivamente para cada formulação entre as horas e para as formulações dentro de cada hora de avaliação.

parte aérea das plantas houve maior acúmulo do sal potássico, comparado ao sal de isopropilamina presente no R. Transorb ${ }^{\circledR}$. A quantidade do R. Ready ${ }^{\circledR}$ foi intermediária à dos demais. Nas raízes, o maior percentual foi observado para R. Transorb ${ }^{\circledR}$, chegando a mais de $30 \% 40$ horas após a aplicação (Figura 5), porém com decréscimo na última avaliação.

Acompanhando o acúmulo de glyphosate nas raízes, foi possível também verificar a translocação para os nódulos. Na primeira 
avaliação, detectou-se o produto, mesmo em quantidade irrisória, na massa seca dos nódulos (Figura 6). A maior proporção de ${ }^{14} \mathrm{C}$ glyphosate foi medida 40 horas após a aplicação, representando aproximadamente 0,13\% do total medido. Houve variação entre as formulações para os tempos de 40 e 64 horas, com maior acúmulo observado em R. Transorb ${ }^{\circledR}$, seguido por Zapp Qi ${ }^{\circledR}$ e, em menor proporção, por R. Ready ${ }^{\circledR}$.

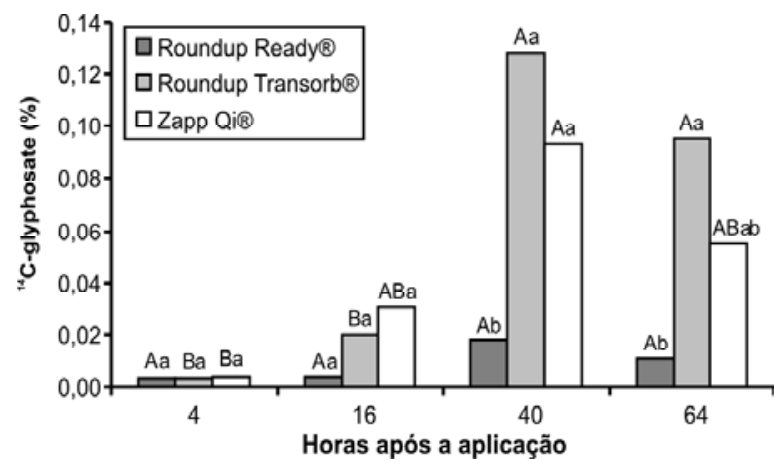

Figura $6-{ }^{14} \mathrm{C}$-glyphosate presente nos nódulos das raízes de plantas de soja (em relação ao total medido) que receberam a aplicação de formulações desse herbicida e posterior quantificação em intervalos de tempo. Colunas sob letras maiúsculas e minúsculas representam médias que não diferem entre si pelo teste de Tukey $(\mathrm{p} \leq 0,05)$, respectivamente para cada formulação entre as horas e para as formulações dentro de cada hora de avaliação.

Trabalhos realizados por Reddy \& Zablotowicz (2003) evidenciaram a participação diferencial dos vários sais de glyphosate (isopropilamina, trimetilsulfônico e diamônio) sobre a massa seca de nódulos da soja transgênica, em que as maiores concentrações detectadas se referiam ao sal de isopropilamina. Em trabalho realizado com estirpes de rizóbio nacionalmente recomendadas para inoculação em sementes de soja, Santos et al. (2005a) observaram que a adição de aminoácidos aromáticos ao meio de cultura diminuiu o efeito inibitório provocado por formulações de glyphosate. Nesse mesmo trabalho, formulações à base do sal isopropilamina mostraram-se mais tóxicas às estirpes de B. elkanii SEMIA 5019 e SEMIA 587 e a B. japonicum SEMIA 5079.

Para se ter uma idéia comparativa entre os sais aplicados nos diferentes intervalos de avaliação, realizou-se o cálculo da distribuição percentual do produto nas partes da planta, descontando a quantidade recuperada na solução de lavagem, avaliando-se o total efetivamente presente na planta (Figura 7). Nas avaliações realizadas 4 e 16 horas após a aplicação do herbicida, observou-se a retenção da maior parte do produto na folha de aplicação. O maior valor $(60,7 \%)$ foi observado para $R$. Transorb ${ }^{\circledR}$, o qual, 16 horas após a aplicação, se apresentou em maior quantidade nos nódulos radiculares $(0,4 \%)$.

De maneira geral, a maior flutuação entre as proporções do produto radiomarcado foi observada entre a parte aérea e as raízes das plantas de soja, independentemente da formulação avaliada. É provável que nos períodos posteriores de avaliação (40 e 64 horas após a aplicação) parte do glyphosate já tenha sido metabolizado a ácido aminometilfosfônico (AMPA). A principal rota de degradação do glyphosate em plantas de soja tolerantes a esse herbicida, denominada rota do AMPA, leva à formação do próprio aminometil ácido fosfônico e glioxilato, a partir do glyphosate. O AMPA, uma vez formado é clivado em metilamina e fosfato inorgânico, como produtos finais de degradação (Hoagland, 1980).

Os resultados obtidos reforçam a hipótese de que o glyphosate pode prejudicar a simbiose entre rizóbio e soja, uma vez que o microssimbionte também apresenta em seu metabolismo a EPSPS, a qual é sensivivel a esse herbicida. 

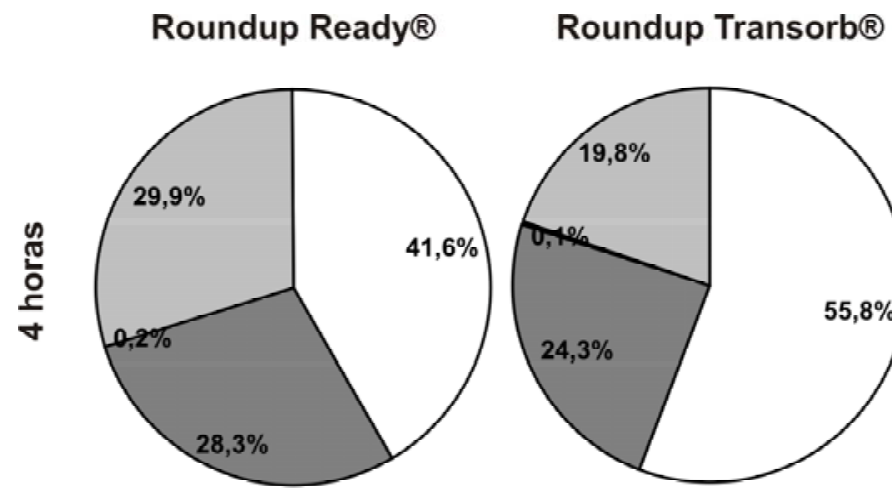

Zapp®
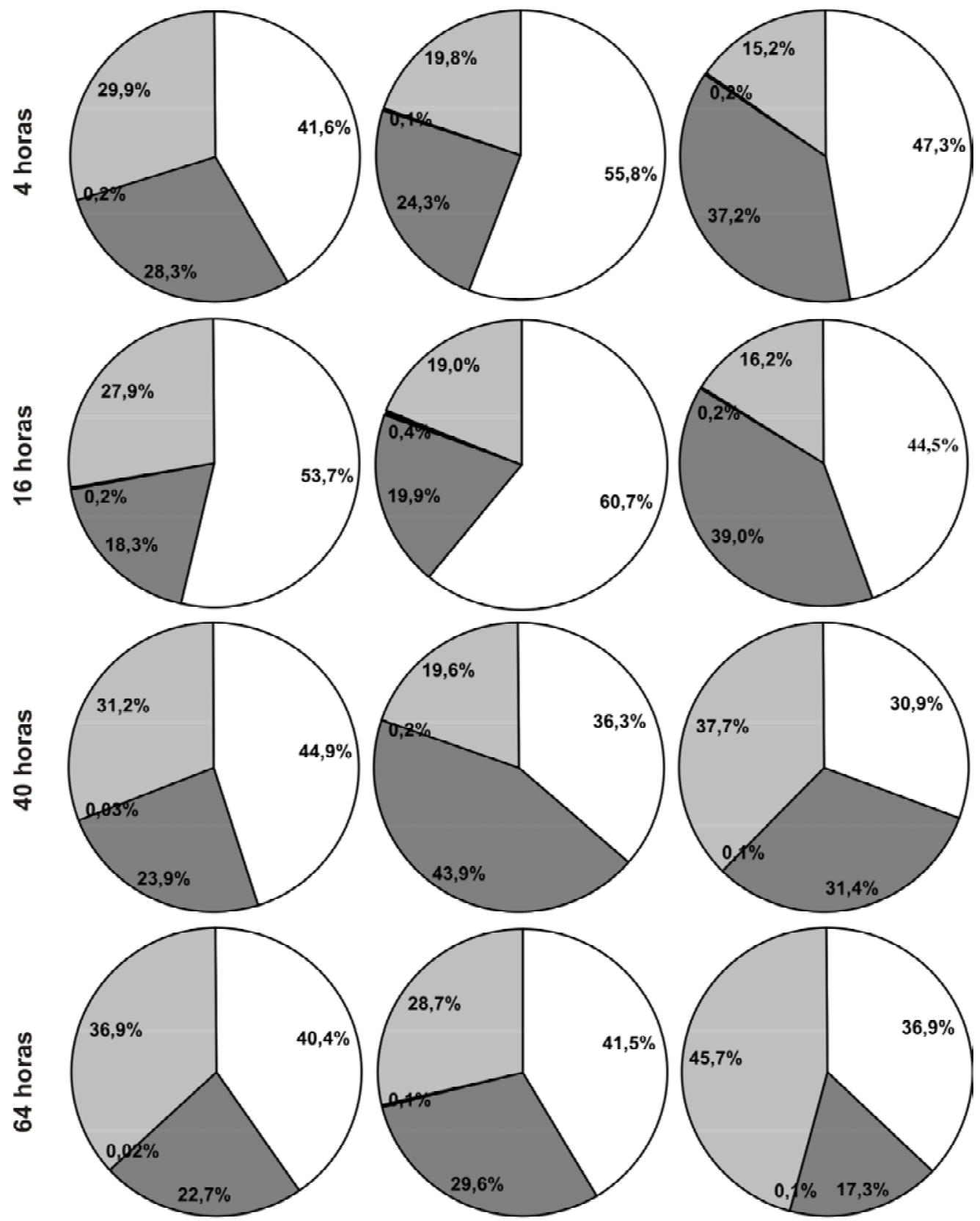

Nódulos

Raizes

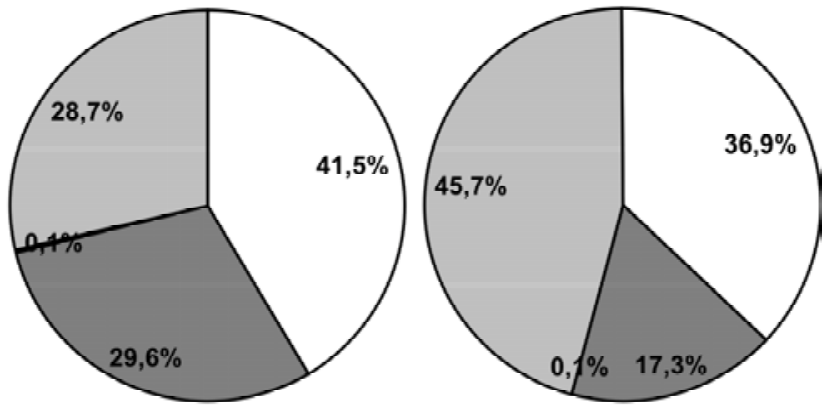

Parte aérea $\square$ Folha aplicada

Figura 7 - Distribuição relativa (\%) de ${ }^{14} \mathrm{C}$-glyphosate, aplicado em diferentes formulações, efetivamente absorvido por plantas de soja e quantific ação em intervalos de tempo. 


\section{AGRADECIMENTOS}

Ao Conselho Nacional de Desenvolvimento Científico e Tecnológico (CNPq), pelo apoio financeiro, e à Coodetec, pelo fornecimento das sementes de soja.

\section{LITERATURA CITADA}

ALMEIDA, L. F. Situação do mercado brasileiro de sementes e o potencial produtivo. Disponível em: $<\mathrm{http}: /$ www.coodetec. com.br/artigo s.asp?id=124> Acesso em: 10 set. 2006 .

BARRY, G. et al. Inhibitors of amino acid biosynthesis: strategies for imparting glyphosate tolerance to crop plants. Current Topics Plant Physiol., v. 7, p. 139-145, 1992.

BRIDGES, D. C. Glyphosate-type herbicidas. In: BRIDGES, D. C. Herbicide action course. West Lafayette: Purdue University, 2003. p. 501-513

DEVINE, M.; DUKE, S. O.; FEDTKE, C. Inhibition of aromatic amino acid synthesis. In: Physiology Herbicide Action. Englewood Cliffs: Prentice Hall. 1993. p. 252263

FERREIRA, E.A. et al. Translocação do glyphosate em biótipos de azevém. Planta Daninha, v. 24, p. 365-370, 2006.

HINCHEE, M. A. W. et al. Herbicide-tolerant crops. In: KUNG, S.; WU, R. (Eds.). Transgenic plants. San Diego: Academic Press, 1993. p. 243-263.

HOAGLAND, R. E. Effects of glyphosate on metabolism phenolic compounds. Weed Sci., v. 28, p. 393-400, 1980.

JAKELAITIS, A. et al. Controle de Digitaria Horizontalis pelos herbicidas glyphosate, sulfosate e glyphosate potássico submetidos a diferentes intervalos de chuva após a aplicação. Planta Daninha, v. 19, p. 279-285, 2001.

MALKONES, H. P. Comparasion of the effects of differently formulated herbicides on soil microbial activities - a review. J. Plant Disease Protec., v. 8, p. 781-789, 2000.
MOLIN, W. T.; HIRASE, K. Effects of surfactants and simulated rainfall on the efficacy of the engane formulation of glyphosate in johnsongrass, prickly sida and yellow nutsedge. Weed Biol. Manag., v. 5, p. 123-127, 2005.

PADGETTE, S. R. et al. New weed control opportunities: Development of glyphosate-tolerant soybeans. In: DUKE, S. O. (Ed.) Herbicide resistant crops. Boca Raton: CRC, 1995. p. $54-80$.

PLINE, W. A.; WU, J.; HATZIOS, K. K. Effects of temperature and chemicals additives on the response of transgenic herbicide-soybeans to glufosinate and glyphosate applications. Pestic. Biochem. Physiol., v. 65, p. 119-131, 1999.

REDDY, K. N.; ZABLOTOWICZ, R. M.REDDY, K. N.; ZABLOTOWICZ, R. M. Glyphosate-resistant soybean response to various salts of glyphosate and glyphosate accumulation in soybean nodules. Weed Sci., v. 51, n. 2, p. $496-502,2003$

RODRIGUES, B. N.; ALMEIDA, F. S. Guia de herbicidas. 5. ed. Londrina: Grafmarke, 2005. 591 p.

SANTOS, J. B. et al. Action of two herbicides on the microbial activity of soil cultivated with common bean (Phaseolus vulgaris) in conventional-till and no-till systems. Weed Res., v. 46, p. 284-289, 2006.

SANTOS, J. B. et al. Tolerance of Bradyrhizobium strains to glyphosate formulations. Crop Protec., v. 24, p. 543-547, 2005a.

SANTOS, J. B. et al. Atividade microbiana do solo após aplicação de herbicidas em sistemas de plantio direto e convencional. Planta Daninha, v. 23, p. 683-691, 2005b.

SANTOS, J. B. et al. Efeitos de diferentes formulações comerciais de glyphosate sobre estirpes de Bradyrhizobium. Planta Daninha, v. 22, p. 293-299, 2004

SHANER, D.; BRIDGES, D. Inhibitors of aromatic amino acid biosyntesis (glyphosate). In: SHANER, D.; BRIDGES, D. Herbicide action course. West Lafayette: Purdue University, 2003. p. 514-529.

SILVA, A. A. et al. Controle de plantas daninhas. Brasília: ABEAS, 2006. 217 p.

WANAMARTA G.; KELLS, J. J.; PENNER. D. Overcoming antagonistic effects of Na-bentazon on sethoxydim absorption. Weed Technol., v. 7, p. 322-325, 1993. 